\title{
GEOFF HEWITT: THEY DON'T MAKE THEM LIKE HIM ANYMORE
}

\author{
Jader R. Barbosa Jr.
}

Department of Mechanical Engineering, Federal University of Santa Catarina, Florianópolis, SC, 88040-900, Brazil; Tel.: +55-48-3234-5166,

Email:jrb@polo.ufsc.br

Original Manuscript Submitted: 7/17/2020; Final Draft Received: 7/26/2020

This article is a personal tribute to the late Professor Geoff Hewitt, one of the founders of this journal and a towering figure in Multiphase Flow. It tells about how his passion for science, professional dedication and kind personality contributed to forging my identity as a scholar and academic advisor.

KEY WORDS: Geoff Hewitt, tribute, multiphase flow

\section{INTRODUCTION}

This article originated from two speeches I delivered in 2019 to remember Geoff Hewitt and celebrate his lifetime achievements. The first speech was given in May at the Hewitt Tribute Session at the International Conference on Multiphase Flow in Rio de Janeiro; the second one was given during an event held at the Department of Chemical Engineering at Imperial College London, in September.

I was extremely humbled by the generosity of Oscar Rodriguez (Chair of ICMF 2019) and Omar Matar (Chair of the Geoff Hewitt Tribute at Imperial College) who invited me to say a few words to honor Geoff Hewitt's memory. Geoff had so many brilliant students who came before and after me, and so many renowned academic collaborators in the UK and overseas, that it was indeed a great responsibility and privilege to speak (and now write) on their behalf.

Geoff was clearly very proud of his students (Fig. 1) and was fond of saying that the theses and dissertations on his shelf (he supervised over $50 \mathrm{PhDs}$ in his career) were his biggest prizes. This is praise indeed coming from someone who received so many accolades during his career.

Professor Hewitt was a benchmark for professional dedication and scientific stewardship in the Multiphase Flow and Thermal Sciences communities that he helped to mold. He was a one-of-a-kind scholar and a gifted engineer with an unparalleled passion for scientific discovery. Those who had the pleasure of working with him were immediately captivated by his encyclopedic knowledge, eidetic memory, relentless dedication to colleagues and students, remarkable concentration skills, great sense of humor and, why not, his fitness, as it was always difficult to catch up with him going up a flight of stairs!

In this article, I would like to share a few of the many unforgettable moments I spent with Geoff, which helped to forge my identity both as a scholar and as an advisor.

\section{MY EARLY DAYS}

I first met Geoff at the 1996 Brazilian Thermal Sciences Meeting in Florianpolis. He was a keynote speaker at the conference. I was finishing my masters at the Federal University of Rio 


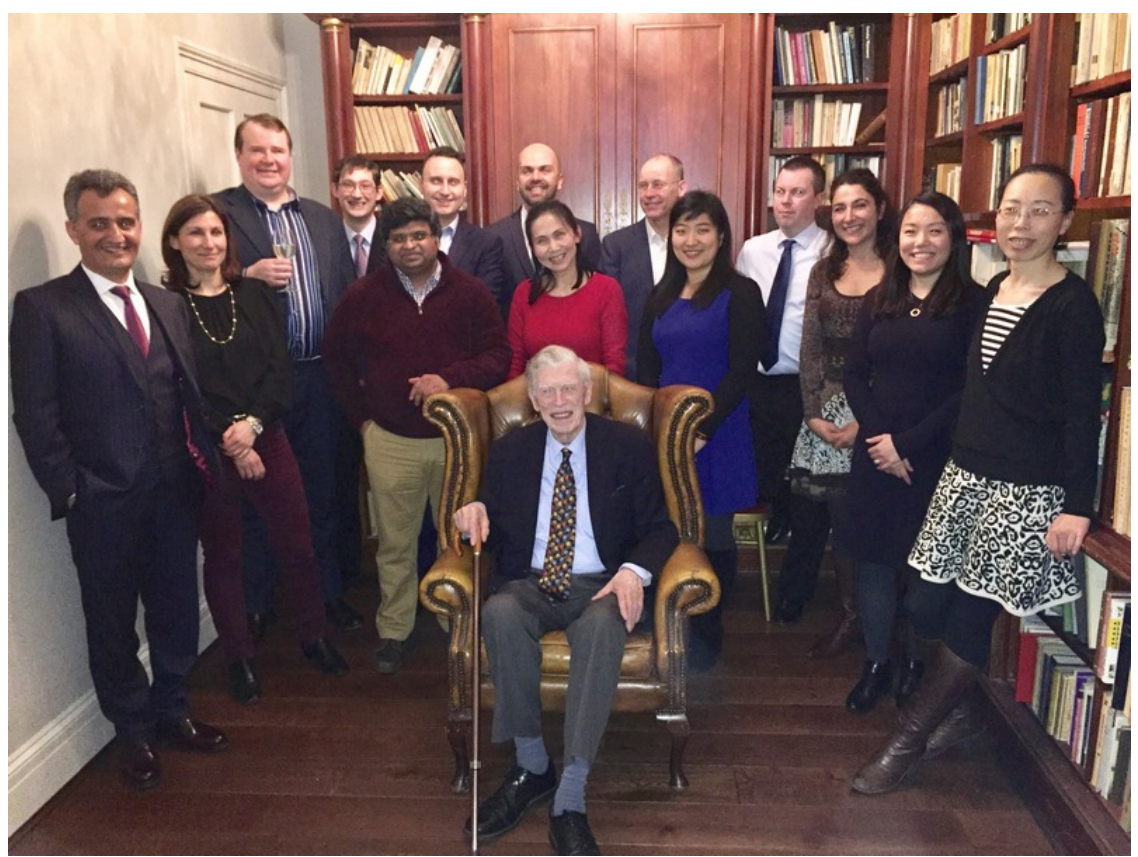

FIG. 1: Picture taken at the Geoff Hewitt's PhD students' reunion on February 25, 2017, at Prince's Gate (near Imperial College). Left to right: Kouroush Tahmasbi, Giota Angeli, Martin Watson, Colin Hale, Prash Valluri, Francesco Coletti, Jader Barbosa, Siew Khor, Arne Wolf, Yujie Zhao, Andrew Hall, Gioia Falcone, Jessy Zeng, and Liu Lan.

de Janeiro and was looking for an opportunity to do a PhD in Multiphase Flow. I had read some of his papers and had already implemented a code in Fortran to solve annular flow using his famous triangular relationship, so I had a pretty good idea who he was in the Multiphase Flow pecking order. I had a reference letter from Renato Cotta (who was then the Brazilian Officer at the International Centre for Heat and Mass Transfer), but I was hesitant to approach Geoff during the conference. Professors Alvaro Prata (of whom I am now a colleague in Santa Catarina) and Atila Freire (my master's supervisor in Rio) helped me with the introduction. Geoff couldn't be kinder and more welcoming. We chatted for a while, I told him about my intention of doing a $\mathrm{PhD}$ with him and handed him the letter. After reading maybe half of it he told me "If Cotta thinks you are this good, then you can come to Imperial."

I remember arriving at Imperial in September of 1997 and preparing for my first meeting with Geoff as a PhD student as if I were going to meet a member of the Royal Family! I knew exactly how privileged I was for having been given the opportunity to work with such a great name in the field of Multiphase Flow and the enormous responsibility that entailed.

There I was sitting in that impressive Professorial Suite on the fourth floor of the Chemical Engineering Building surrounded by books, filing cabinets, and gifts from around the world. The next thing I notice on the table is a hanging folder with all the correspondence Geoff and I had exchanged in the year before. On the tab, my name was written next to a number: Jader Barbosa — GFC 13.88. I was officially in. ${ }^{\ddagger}$

${ }^{\ddagger}$ GFC stood for General File College. 


\section{BECOMING A PART OF IT}

Geoff was extremely organized and had the most amazing filing system. The file folder cabinets covered one wall of his office on the fourth floor. When he retired in 1999 and became Professor Emeritus, he moved to a smaller office on the fifth floor. He asked three of his PhD students (Phil Manfield, Utomi Odozi, and I) to help move his books and files to the new office. It took us a whole morning to transfer all the stuff and organize it properly. ${ }^{\S}$ He gave each one of us fifty quid, but of course we would have done it for nothing.

The process of preparing notes for progress meetings with Geoff was always a memorable experience. During the meetings, notes were recorded using a hand-held Dictaphone, and the students had to transcribe the tapes and print the notes for Geoff's files. Every so often, during a meeting, somebody would knock on the door or his phone would ring. He could chat for minutes with the person at the door or at the other end of the line about an entirely different subject. Then, he would come back and sit down at the table, pick up the Dictaphone, close his eyes and start dictating again in order to finish the sentence-sometimes without rewinding the tape-it was remarkable what amazing concentration skills that Geoff possessed.

I remember one day when I accidentally erased my tape while typing the notes of a previous meeting, I ran back to him in despair and was told very naturally, "but can't you remember?" Then I realized that the Dictaphone business was not for him, but for us. He had it all in his head.

Despite being extremely busy, Geoff tried to follow his students' progress very closely. In addition to the progress meetings, he would pop into the students' office on the fourth floor to check on us on a regular basis: "Any progress?", "How is it going?" was usually how he would start a conversation. "Have you tried this?" or "Have you tried that?" were also often heard if neither of us were too convinced about the latest result. "Ok! So, why don't you write a paper about it?" was often how a successful corridor meeting would end.

Post-it notes and letterheads were also an effective means of communication with the students. I still keep many of them to this day (Figs. 2 and 3). Every month - at a time when online journals were still in their infancy-he would drop the latest issues of the International Journal of Multiphase Flow or the International Journal of Heat and Mass Transfer at the students' office with a large post-it note on the cover:

"For CINBIN":

1. Page A: Badie;

2. Page B: Barbosa;

3. Page C: Watson;

4. Page D: Shaha;

5. Page E: Hale;

6. GFH."

"A very good issue!" he would write on the post-it notes sometimes.

\footnotetext{
$\S$ Those who know Colin Hale and his amazing design skills and capability to generate data would not be surprised to learn that he had the thickest file of all!

${ }^{\top}$ CINBIN (Central Identification Number Bin) was a paper/report repository maintained by the students and researchers in our office on the fourth floor (Room 401). Every paper that was copied and entered had a unique identifying number in the electronic database that accompanied all the filing cabinets of papers.
}

Volume 32, Issue 3, 2020 


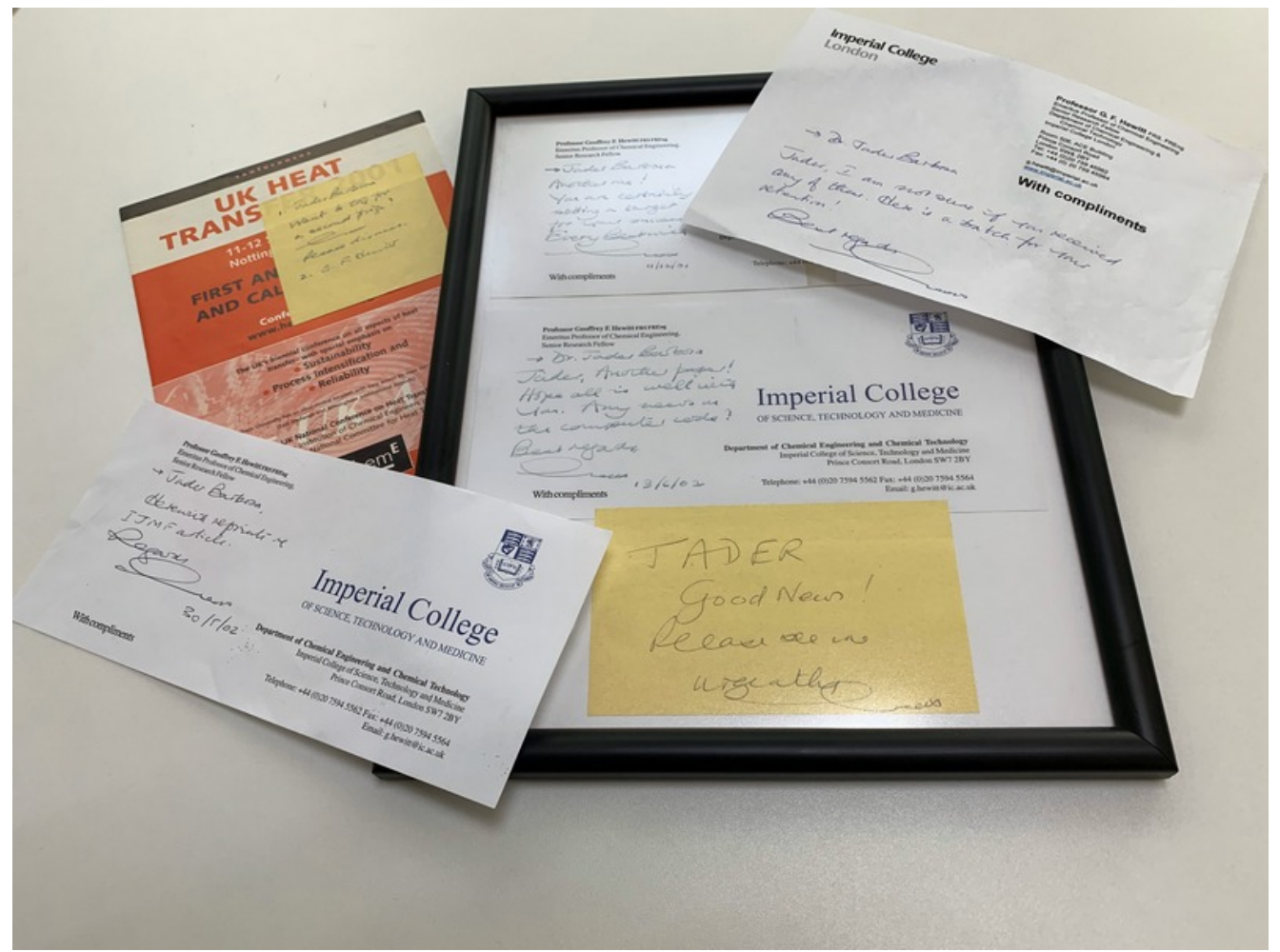

FIG. 2: Letterheads and post-it notes from GFH

Perhaps the most remarkable moment I had with Geoff was when I was finishing my first year as a PhD student. In one of our meetings I showed him my calculations on droplet concentration imbalance and how my results explained the deterioration of the flow boiling heat transfer coefficient in annular flow of mixtures observed experimentally by Thomas Kandlbinder at Harwell. His enthusiastic reply "Oh! There is nothing like it, Jader! Nothing beats this feeling!" summed up his passion for science and the eternal flame of curiosity which burned through his entire career. To me, this is essentially what such an incredible guy like Geoff was about.

To many, including myself, Geoff was the quintessential professorial figure. Yet for a man of his scientific stature, he was never intimidating. As time went by, one would quickly learn to feel at ease around him, for generosity and kindness were key attributes of his personality. "Take the day off. Go to the opera. Have you been to Somerset House?" was the kind of advice you would get from him if he felt you were frustrated with something and needed to recharge your batteries.

Barry Azzopardi always reminded us of how thankful he was for the space Geoff gave him during his early career at Harwell. I never truly understood the dimension of Barry's comment until I became a (seasoned) supervisor myself. I have to admit that it is not an attribute that comes with the job.

At the same time Geoff was sharing with us his vast knowledge on a range of subjects, he was also giving all of us intellectual freedom to develop ideas of our own. However, I must confess it was not easy to come up with truly original ideas around Geoff, for if he himself had not done 


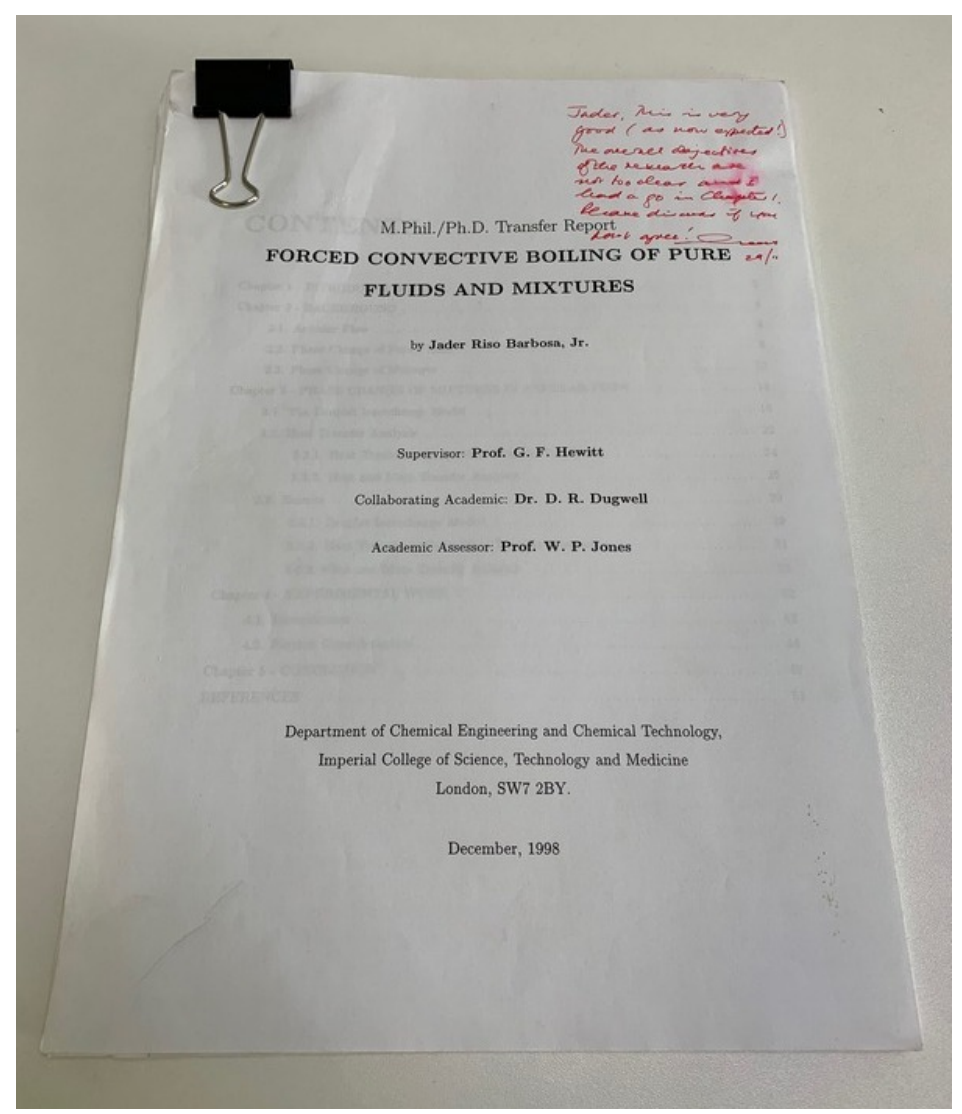

FIG. 3: Marked copy of my MPhil/PhD. Transfer Report. The note from GFH reads: "Jader, this is very good (as now expected!). The overall objectives of the research are not too clear, and I had a go in Chapter 1. Please discuss if you don't agree! Geoff 29/11.”

exactly the same thing before, he knew exactly who had done or attempted to do something similar back in Harwell in the 1960s. And chances were that the Harwell design for the mixer, separator, heater, or test section (Fig. 4) would be ten times better than the one you were trying to come up with. The top shelves in Geoff's office, where he kept his old Harwell reports, were the Oracle of my PhD years.

Geoff's legendary wit and sense of humor often found their way into the titles of his publications and lectures. "To Churn or not to Churn" (Hewitt and Jayanti, 1993), "Churn Flow: Myth, Mystery and Magic" (Barbosa et al., 2001), "Multiphase Flow: The Gravity of the Situation" (Hewitt, 1996) and "Goodbye Thermodynamic Equilibrium" (Hewitt, 2007) are a few examples which come to my mind. Even the most heated debate with Professor Abraham Dukler (University of Houston) on the existence of churn flow-one of Geoff's dearest subjects-became somewhat amusing to the readers of the International Journal of Multiphase Flow (Mao and Dukler, 1993; Hewitt and Jayanti, 1993).

${ }$ This was the title of his keynote at the Third Microgravity Fluid Physics Conference (Cleveland, OH, 1996), which I find particularly amusing!

Volume 32, Issue 3, 2020 


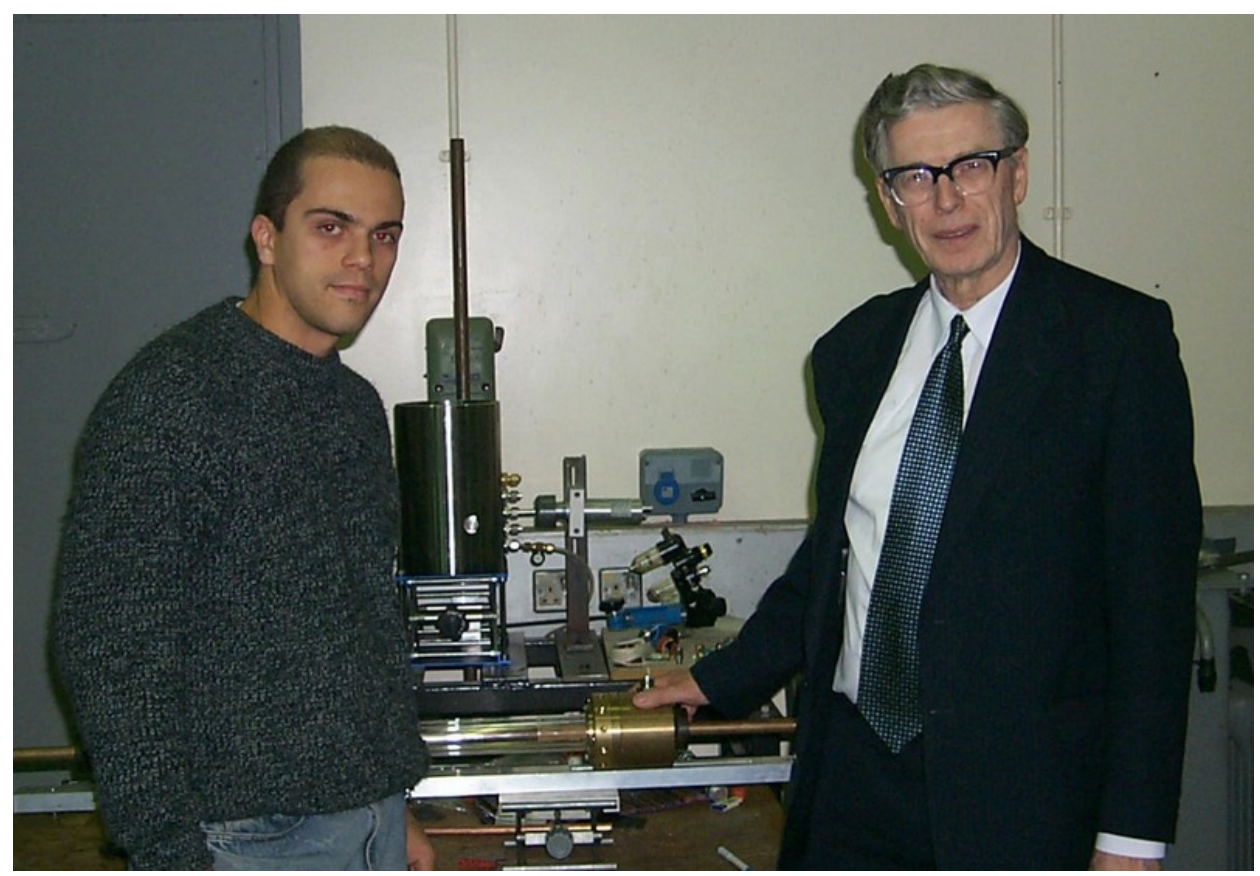

FIG. 4: Geoff and I in the lab in room 111A of the Chemical Engineering Building at Imperial. Geoff is holding the recently assembled annulus flow boiling test section I designed and tested during my PhD. A similar test section had been built at Harwell years before to investigate the interaction between disturbance waves and nucleation sites in annular flow. Though he hardly spent time in the lab, it always impressed us how much he knew about every tiny detail of each rig and their capabilities by heart.

\section{FROM STUDENT TO COLLABORATOR}

After I finished my $\mathrm{PhD}$, in 2001, I came back to Brazil and took a position as an Assistant Professor at the Federal University of Santa Catarina, in Florianpolis (which coincidentally is the place Geoff and I had met a few years earlier). However, we continued to collaborate on a few topics on phase change heat transfer (from slug flow thermal nonequilibrium to condensation) and wellbore modeling (which allowed me to continue to work with Gioia Falcone as well).

I also helped Geoff with editorial tasks involving the Heat Exchanger Design Handbook (initially) and later Thermopedia. We worked on some consultancy projects together, which kept me coming back to Imperial once a year for a week or so. Those visits were always a good opportunity for me to show him my students' works and try to get some feedback or insights from him.

In one such visit in 2013, I was eager to show him some fresh results on gas-liquid flows in U-bends. Pedro Oliveira (a very good master's student with a natural talent for experimental work) and I put together a transparent two-phase flow loop in my lab where we could make beautiful high-speed recordings and measure simultaneously the void fraction and the pressure drop associated with the bend (which strangely enough was something the literature was lacking). I was quite excited to show him the videos of liquid slugs and disturbance waves going up and down the bend and discuss our results. ${ }^{* *}$ As we watched the videos and chatted, Geoff

\footnotetext{
${ }^{* *}$ The full video made by Pedro Oliveira and I can be seen at: https://vimeo.com/80609996
} 
said: "You know, there was a guy named George who did similar experiments at Harwell... We wanted to look at the behavior of disturbance waves downstream from the bend. We wanted to understand their influence on dry out." As he gets up, I think to myself "Oh, dear! He's reaching for the top shelf again, isn't he?" Then, he grabs a roll of 16-mm film (or how Geoff would call it, "ciné film") and gives to me. "You will have to find a projector to play this thing," he says.

So, I fly back home and immediately Pedro and I grab hold of this cinephile in Florianpolis who had a vintage projector and had agreed to collaborate with us. To our surprise, what we saw in the Harwell footage was remarkably similar to the experiment done in my lab more than four decades later! $!^{\dagger \dagger}$ I remember feeling helpless for knowing that it was impossible to beat those Harwell folks by coming up with something completely new, but at the same time happy to have learned so much from them and proud to carry on their legacy.

To finish my tribute, I would like to say that I am very lucky to have had Geoff Hewitt as a supervisor, mentor, and friend, and to have been a research collaborator of his for so many years (Fig. 5). I am very grateful for the opportunities he gave me since I was a student and for always - often without saying a word-reminding me of how fortunate we are to work on stuff that gives so much pleasure.

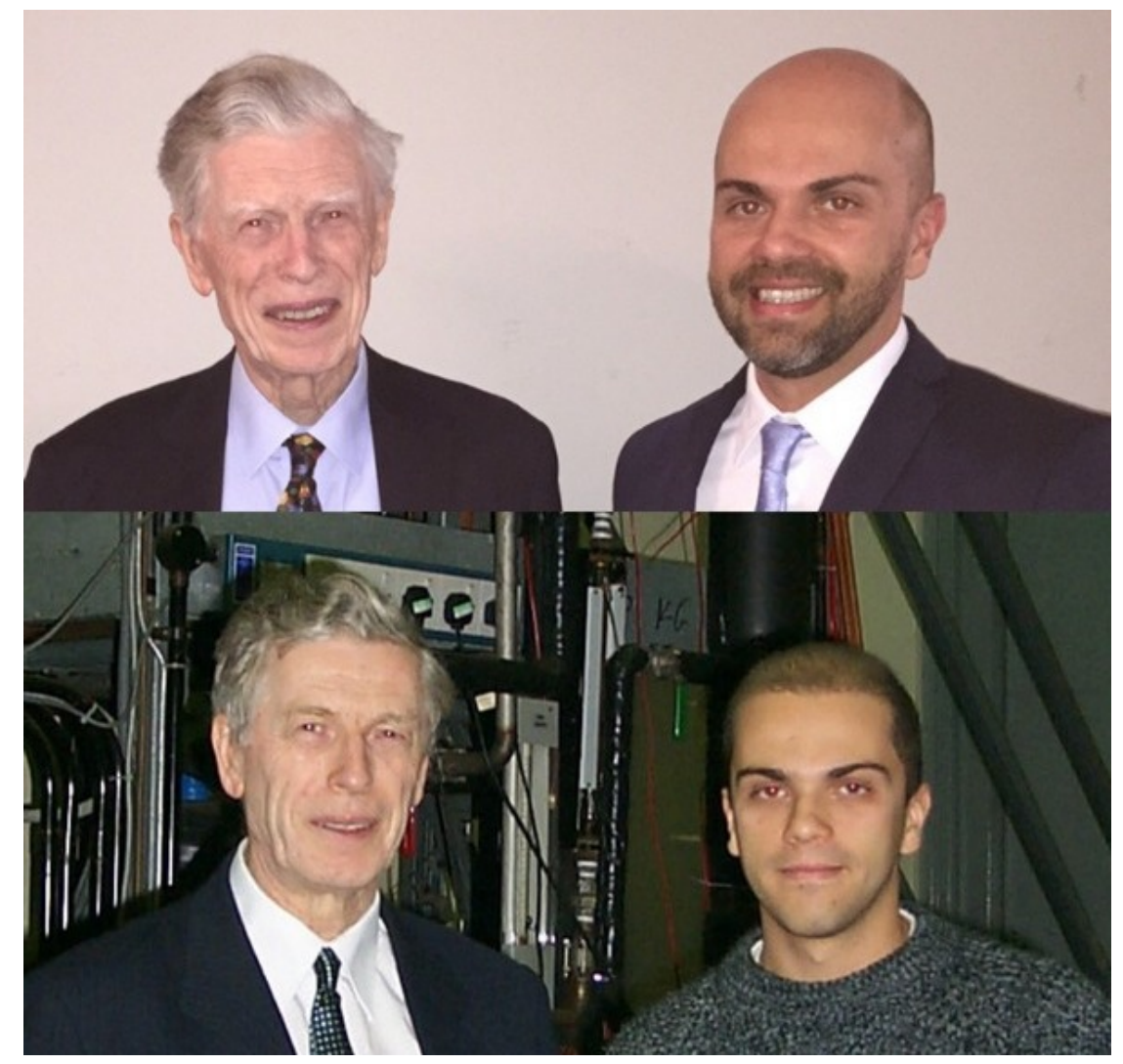

FIG. 5: Top: 2017. Bottom: 1999.

\footnotetext{
${ }^{\dagger \dagger}$ The Harwell video can be seen at: https://vimeo.com/79145683. It ends in great style with images from an axial viewing setup!
}

Volume 32, Issue 3, 2020 


\section{ACKNOWLEDGEMENT}

Thanks to Gioia Falcone and Colin Hale for reading earlier versions of the manuscript.

\section{REFERENCES}

Barbosa, J.R., Jr., Hewitt, G.F., and Richardson, S.M., Churn Flow: Myth, Mystery and Magic, Eur. TwoPhase Flow Group Meeting, Aveiro, Portugal, June 18-20, 2001.

Hewitt, G.F., Multiphase Flow: The Gravity of the Situation, Third Microgravity Fluid Physics Conference (Keynote Address), Cleveland, OH, 1996.

Hewitt, G.F., Goodbye Thermodynamic Equilibrium, 16th School Seminar of Young Scientists and Specialists on the Problems of Heat and Mass Transfer and Gas Dynamics in Power Plants, St. Petersburg, Russia, 2007.

Hewitt, G.F. and Jayanti, S., To Churn or not to Churn, Int. J. Multiphase Flow, vol. 19, no. 3, pp. 527-529, 1993.

Mao, Z.S. and Dukler, A.E., The Myth of Churn Flow?, Int. J. Multiphase Flow, vol. 19, no. 2, pp. 377-383, 1993. 